\title{
Peer-led versus teacher-led AIDS education for female high-school students in Yazd, Islamic Republic of Iran
}

M.H. Baghianimoghadam, ${ }^{1}$ H. Forghani, ${ }^{1}$ R. Zolghadr, ${ }^{1}$ Z. Rahaei ${ }^{1}$ and P. Khani ${ }^{2}$

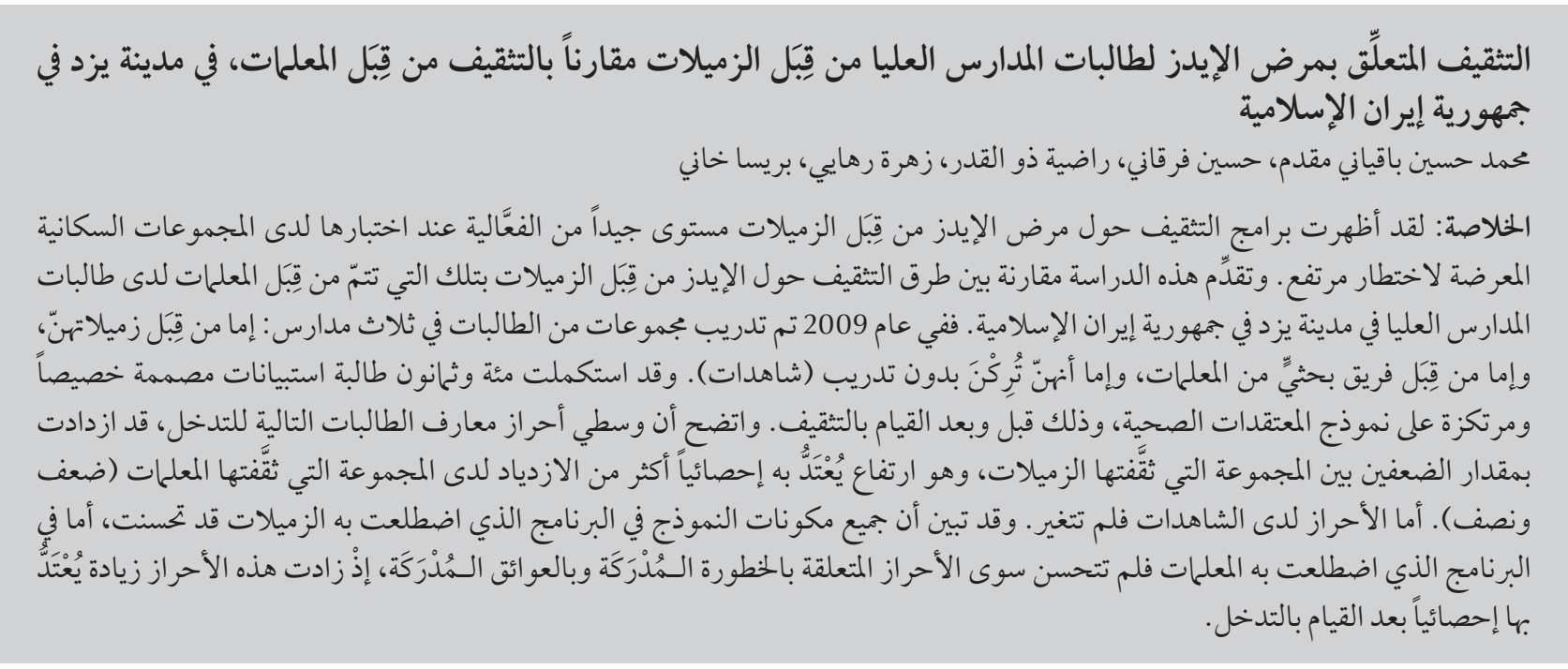

ABSTRACT Peer-led programmes on AIDS prevention have shown a good level of effectiveness when tested among high-risk populations. This study compared peer-led and teacher-led methods of education about HIV/AIDS among female high-school students in Yazd city, Islamic Republic of Iran. In 2009 students in 3 high schools were trained by their classmates (peer-led), by the research team (teacher-led) or had no education (controls); 180 students completed a specially designed questionnaire based on the health belief model, before and after the intervention. Post-intervention mean knowledge scores increased 2-fold in the peer-led group, and this was significantly higher than the increase in the teacher-led group scores (1.5-fold). Control group scores were unchanged. In the peer-led programme all of the components of the model were significantly improved whereas in the teacher-led programme, only perceived severity and perceived barriers scored significantly higher after the intervention.

Comparaison de l'éducation sur le sida menée par des pairs ou par des enseignants auprès de lycéennes à Yazd (République islamique d'Iran)

RÉSUMÉ Les programmes de prévention du sida menés par des pairs ont démontré un bon niveau d'efficacité lors des tests dans des populations à haut risque. La présente étude a comparé les méthodes d'éducation sur le VIH/ sida menées par des pairs ou par des enseignants auprès de lycéennes dans la ville de Yazd (République islamique d'Iran). En 2009, des lycéennes de trois établissements secondaires ont été formées par leurs camarades de classe (des pairs), par l'équipe de recherche (des enseignants), ou n'ont pas reçu de formation (groupe témoin). Au total, 180 lycéennes ont rempli un questionnaire élaboré pour l'occasion et reposant sur un modèle de croyances relatives à la santé, avant puis après l'intervention. Les scores moyens relatifs aux connaissances après l'intervention avaient doublé dans le groupe formé par des pairs. Cette augmentation était nettement supérieure à celle des résultats du groupe formé par des enseignants (1,5 fois). Les scores du groupe témoin n'ont pas évolué. Dans le programme mené par des pairs, toutes les composantes du modèle avaient augmenté de manière significative alors que dans le programme mené par des enseignants, seules les composantes relatives à la perception de la gravité et des obstacles avaient augmenté après l'intervention.

'Faculty of Health, Shahid Sadoughi University of Medical Sciences, Yazd, Islamic Republic of Iran (Correspondence to H. Forghani: dr.forghani@ gmail.com).

${ }^{2}$ Research and Clinical Center for Infertility, Shahid Sadoughi University of Medical Sciences, Yazd, Islamic Republic of Iran.

Received: 17/01/10; accepted: 25/07/10 


\section{Introduction}

In the Islamic Republic of Iran, as in some other parts of the world, the prevalence of human immunodeficiency virus (HIV) has been rising in recent years. The prevalence of HIV in this country was 2 per 100000 in 2004. Based on the most recent data published by the Ministry of Health and Medical Education there were 13357 Iranians living with HIV/AIDS in 2006, of whom $94.5 \%$ were male and $5.5 \%$ were female [1]. An important factor fuelling the spread of HIV/AIDS in developing countries is believed to be poor knowledge about how the disease is spread and how it can be prevented. In the study by Tavoosi et al. in 2004 it was shown that knowledge of students in the Islamic Republic of Iran about HIV/AIDS was only moderate [2]. It is therefore very important to educate the population for preventing the spread of HIV/AIDS.

Many studies have been carried out in the field of peer education on HIV/AIDS among young people. Programmes that focus on changing behaviours by promoting skills in communication, negotiation and refusal in response to social and media pressure have been shown to be more effective than others [3,4]. However, doubts persist about who should be entrusted with conducting such interventions. In other fields, peer-led educational programmes have succeeded in delaying the onset of cigarette smoking [5] or other drug use [6,7]. In AIDS prevention, peer-led programmes have shown a good level of effectiveness when tested among high-risk populations, such as intravenous drug users and their partners, prostitutes and adolescents at high-risk $[8,9]$ and among gay men [10-12]. This success has been attributed to the fact that members of the target population were directly involved in redefining and communicating to their peers social norms on the prevention of at-risk sexual behaviour. While global efforts to understand and improve the process and impact of peer education in the area of HIV/AIDS prevention have increased, the implementation of peer-led prevention programmes within a young school population is still controversial [6].

The objective of the present study was to determine the effectiveness of peer-led education when compared with current curricula in AIDS prevention programmes conducted at high schools in Yazd, Islamic Republic of Iran.

\section{Methods}

\section{Setting and sample}

This comparative study was carried out in spring 2009. A total of 180 female students were randomly selected from 3 high schools $(n=60$ in each school) in Yazd city, Islamic Republic of Iran. The high schools were selected by cluster sampling from the list of high schools at the Department of Education of Yazd province. The students were first-year students studying in the fields of literature, science or mathematics. The study was approved by the ethics committee of Shahid Sadoughi University of Medical Sciences and Health Services.

\section{Intervention}

Different educational models were applied for each high school. The students of one high school were assigned to peer-led education (peer-led group), the students of another high school to a teacher-led educational programme (teacher-led group) and the students of the third high school were a control group from a different area of the city who did not have any AIDS education.

For the peer-led education intervention, a preliminary meeting involving teachers of every selected class, the headmaster of the high school and the researchers defined the criteria for the selection of peer leaders according to suggestions from the literature (charismatic personality, credibility, capacity in communicating and relationships with other students). The 9 peer leaders who were selected by the headteacher of the high school and some teachers of selected classes (3 students in every class) attended an 8-hour residential training course led by the researchers (who had expertise in health education, general practice and public health). During this they were trained in the use of interactive methods for conducting the intervention and the use of the educational materials.

The intervention was based on materials developed by the Joint United Nations Programme on HIV/AIDS (UNAIDS) [13] and included slides, brochures, lectures and face-to-face teaching. The total length of the intervention was 5 hours, conducted over 3 sessions. The teacher-led group was trained by the researcher team with the same materials that were used for the peer-led group. Both the peer-led and teacher-led education interventions were based around the behaviour change theory of the health belief model (HBM).

\section{Data collection}

The data were collected using a specially designed questionnaire, based on the constructs of the HBM [14], consisting of 6 sections: information on individual social and demographic characteristics and other health-related behaviour (7 questions), knowledge about HIV and AIDS (26 questions, score range 0-34), perceived susceptibility about HIV and AIDS (8 questions, score range 0-32), perceived severity about HIV and AIDS (6 questions, score range of $0-24$ ), perceived benefits ( 3 questions, score range $0-12$ ) and perceived barriers (4 questions, score range 0-16). Questions were scored on a 5-point Likert scale (from $4=$ strongly agree to $0=$ strongly disagree). The questionnaire was distributed before the intervention (pre-test) and 2 months afterwards (post-test). All 180 students completed both questionnaires. 
The internal consistency of the questionnaire was calculated using the test-retest technique among 15 similar subjects who did not participate in the final study. The overall reliability coefficient for the questionnaire was 0.82 .

\section{Data analysis}

All data were collected and transferred directly to SPSS, version 16. Data were presented as mean and standard deviation (SD) scores of students before and after the intervention. For data analysis, Kruskal-Wallis, Mann-Whitney, Spearman correlation and Wilcoxon were used and level of confidence interval was $95 \%$.

\section{Results}

Before the intervention there was no significant difference between the 3 groups in terms of demographic characteristics such as parent's education and parent's age. The results also showed that mean scores on knowledge and components of the HBM (perceived susceptibility, perceived severity, perceived benefits and perceived barriers) were not significantly different between the 3 groups before the intervention (Table 1).

After the intervention the mean knowledge scores of the peer-led group increased more than 2-fold, from 15.9 (SD 4.4) to 33.7 (SD 1.9) out of 34), whereas a lower increase was seen in the teacher-led group, from 14.8 (SD $4.5)$ to 22.3 (SD 6.8). The knowledge scores of the control group remained the same over the 2-month time period [15.6 (SD 5.0) versus 15.8 (SD 4.9)] (Table 1).

After the intervention there was a highly significant increase in the peer led-group in mean scores on knowledge $(P<0.001)$ and all of the constructs of the HBM $(P<0.001$ for perceived susceptibility, perceived severity and perceived barriers and $P<0.021$ for perceived benefits) (Table 1). In the teacher-led group, there were significant increases in knowledge, perceived severity and perceived barriers $(P<0.001)$, but there was no significant difference

\begin{tabular}{|c|c|c|c|}
\hline Construct of HBM/intervention group & $\begin{array}{c}\text { Before intervention } \\
\text { Mean (SD) }\end{array}$ & $\begin{array}{c}\text { After intervention } \\
\text { Mean (SD) }\end{array}$ & $P$-value ${ }^{a}$ \\
\hline \multicolumn{4}{|l|}{ Knowledge } \\
\hline Peer-led & $15.9(4.4)$ & $33.7(1.9)$ & $<0.001$ \\
\hline Teacher-led & $14.8(4.5)$ & $22.3(6.8)$ & $<0.001$ \\
\hline Control & $15.6(5.0)$ & $15.8(4.9)$ & 1.0 \\
\hline$P$-value ${ }^{b}$ & 0.212 & $<0.001$ & \\
\hline \multicolumn{4}{|l|}{ Perceived susceptibility } \\
\hline Peer-led & $20.1(4.5)$ & $29.3(2.7)$ & $<0.001$ \\
\hline Teacher-led & $22.5(4.1)$ & $23.5(5.7)$ & $<0.081$ \\
\hline Control & $21.1(4.0)$ & $21.8(4.2)$ & 1.0 \\
\hline$P$-value ${ }^{\mathrm{b}}$ & 0.11 & $<0.001$ & \\
\hline \multicolumn{4}{|l|}{ Perceived severity } \\
\hline Peer-led & $12.9(7.5)$ & $18.4(2.1)$ & $<0.001$ \\
\hline Teacher-led & $12.5(2.9)$ & $14.9(6.8)$ & $<0.001$ \\
\hline Control & $11.8(2.8)$ & $12.1(2.6)$ & 0.285 \\
\hline$P$-value ${ }^{b}$ & 0.669 & $<0.001$ & \\
\hline \multicolumn{4}{|l|}{ Perceived benefits } \\
\hline Peer-led & $9.1(2.6)$ & $10.0(2.5)$ & 0.021 \\
\hline Teacher-led & $8.7(2.4)$ & $9.4(2.0)$ & 0.066 \\
\hline Control & $9.4(2.0)$ & $9.5(1.9)$ & 0.317 \\
\hline$P$-value ${ }^{b}$ & 0.264 & 0.024 & \\
\hline \multicolumn{4}{|l|}{ Perceived barriers } \\
\hline Peer-led & $9.0(3.4)$ & $14.4(3.1)$ & $<0.001$ \\
\hline Teacher-led & $9.6(3.5)$ & $11.6(3.5)$ & $<0.001$ \\
\hline Control & $9.9(3.2)$ & $9.7(3.0)$ & 0.075 \\
\hline$P$-value ${ }^{b}$ & 0.209 & $<0.001$ & \\
\hline
\end{tabular}

${ }^{a}$ Wilcoxon test; ${ }^{b}$ Kruskal-Wallis test.

$S D=$ standard deviation . 
for perceived susceptibility $(P=0.081)$ and perceived benefits $(P=0.066)$. In control group there were no significant differences in scores on knowledge or any of the constructs of the HBM.

Before the intervention, as shown in Table 1, there was no significant difference between the 3 groups (peerled, teacher-led and controls) in mean scores on knowledge and all constructs of the HBM. After the intervention there were significant differences between groups in knowledge and all HBM constructs $(P<0.001$ and $P=0.024$ for perceived barriers).

Table 2 shows the change in mean scores before and after the intervention. There was a significant difference between students in their knowledge according to their subject of study ( $P$ $=0.05)$. The knowledge of students studying literature increased more than the students of science or mathematics. There was no significant difference between scores on the constructs of the HBM and subject studied $(P>0.5)$.

\section{Discussion}

The study results showed that both the peer-led and the teacher-led interventions seemed to have induced improvements in knowledge, perceived susceptibility to HIV/AIDS, perceived severity of risk, perceived benefits and perceived barriers to change. While knowledge was significantly improved in the peer-led group compared with the teacher-led group, there were no changes in the control group before and after the intervention. These results are similar to those of Borgia et al. in Italy, who demonstrated that the peerled and teacher-led interventions both seemed to have induced improvement in knowledge, attitudes, risk perception and prevention skills and the peer-led method showed greater improvement in the level of knowledge about the HIV transmission and prevention [15]. In our study significant changes in the knowledge of both intervention groups and no changes in control group after the intervention indicated that the educational sessions, both teacher- and peer-led, were effective in improving the student's knowledge.

Numerous studies have evaluated the effects of peer-led educational programmes on high-risk populations, and different levels of effectiveness have been reported [10-12]. Mellanby et al. in the United Kingdom demonstrated that the results from adult-led school sex education were less effective than those delivered by peer-led programmes. The students in the intervention indicated that they were embarrassed during the peer-led sessions compared with adultled sessions [16]. Mellanby et al. also reported that $76 \%$ of students in a peer-led group approved of their sex education compared with $42 \%$ of controls [17].

Using the HBM as the framework to help understand health-related behaviour, specifically attitudes to highrisk behaviours for HIV transmission, our results showed that after the peer-led programme all of the components of the model were significantly improved whereas in the teacher-led programme, only perceived severity and perceived barriers scored significantly higher. That is, in the peer-led programme, students reduced their perceptions of HIV highrisk behaviours when they believed in the effectiveness of strategies designed to reduce the risk or when they believed in the seriousness of the health condition. This does not mean that in the teacherled programme other components of the HBM were not effective in explaining attitudes to health-related behaviour.

Similar to the findings in our study, a study among Iranian prisoners showed that the only component of the HBM that was significantly associated with reduction of high-risk behaviour was perceived benefit [18]. Our results are not consistent with the results of Hounton et al. in rural Benin, who identified perceived efficacy (incomplete protective effect) and perceived utilization-related problems (any reported problem using condoms) as the main barriers to condom use [19]. Hence preventions strategies based on increasing perceived risk, perceived severity or adequate knowledge about HIV/AIDS may not be sufficient to induce condom use, for example. These results suggest that different methods may have different outcomes.

\begin{tabular}{|c|c|c|c|c|}
\hline \multirow[t]{2}{*}{ Variable } & $\begin{array}{l}\text { Literature } \\
\quad(n=35)\end{array}$ & $\begin{array}{l}\text { Science } \\
(n=18)\end{array}$ & $\begin{array}{c}\text { Mathematics } \\
(n=12)\end{array}$ & $P$-value ${ }^{a}$ \\
\hline & Mean (SD) & Mean (SD) & Mean (SD) & \\
\hline Knowledge & $47.2(19.0)$ & $17.8(4.6)$ & $14.4(6.3)$ & $P<0.05$ \\
\hline Perceived susceptibility & $5.4(9.4)$ & $8.6(4.7)$ & $6.0(9.5)$ & $P=0.729$ \\
\hline Perceived severity & $9.6(4.7)$ & $6.6(3.2)$ & $6.1(3.6)$ & $P=0.871$ \\
\hline Perceived benefits & $1.6(2.9)$ & $0.6(4.3)$ & $0.3(4.3)$ & $P=0.732$ \\
\hline Perceived barriers & $14.6(4.9)$ & $5.8(3.7)$ & $4.4(4.2)$ & $P=0.557$ \\
\hline
\end{tabular}

${ }^{a}$ Kruskal-Wallis test.

$S D=$ standard deviation 
Awareness of and discussion about HIV/AIDS still remains limited among many sectors of Iranian society, including adult girls. For risky behaviours related to sexuality, this may be due to the fact that sexual behaviour outside of marriage is still taboo in the country and is not openly discussed, especially in this age group. Interventions such as ours may not be acceptable to parents and the educational system and are likely to be censored. It should therefore be noted that we performed this study in the context of these cultural barriers. Hasanian's study in Muslim countries showed that in the field of AIDS prevention risk behaviour education needs take account of the religious and social norms of the society [20].

Our results seem to confirm the theoretical basis and previous research findings of peer-led influences on health education $[21,22]$. Those studies did not investigate why peer-led education might be more effective. Peer-led programmes may be more influential as role models or may be more popular. Further investigation into students' perceptions of such programmes would provide a greater insight into these factors.

\section{References}

1. HIV/AIDS in Iran. UNICEF [online factsheet] (http://www. Unicef.org/iran/media_2016.html, accessed 18 January 2012).

2. Tavoosi A et al. Knowledge and attitude towards HIV/AIDS among Iranian students. BMC Public Health, 2004, 4:17.

3. Choi KH, Coates J. Prevention of HIV infection. AIDS, 1994, 8:1371-1389.

4. Kirby D. School-based interventions to prevent unprotected sex and HIV among adolescents. In: Peterson JL, DiClemente RJ. Handbook of HIV prevention. New York, Kluwer Academic/ Plenum Publishers, 2000:83-97.

5. Kirby D et al. An impact evaluation of project SNAPP: an AIDS and pregnancy prevention middle school programme. AIDS Education and Prevention, 1997, 9(Suppl.):A44-A61.

6. Perry CL, Grant M. Comparing peer-led to teacher-led youth alcohol education in four countries. Alcohol Health and Research World, 1988, 12:322-326.

7. Klepp KI, Halper A, Perry CL. The efficacy of peer leaders in drug abuse prevention. Journal of School Health, 1986, 56:407-411.

8. Centers for Disease Control and Prevention. Communitylevel prevention of human immunodeficiency virus infection among high-risk populations: the AIDS Community Demonstration Projects. Morbidity and Mortality Weekly Report, 1996, 45:1-16.

9. CDC AIDS Community Demonstration Projects Research Group. Community-Level HIV Intervention in 5 cities: final outcome data from the CDC AIDS Community Demonstration Projects. American Journal of Public Health, 1999, 89:336-345.

10. Kelly JA et al. HIV risk behavior reduction following intervention with key opinion leaders of population: an experimental analysis. American Journal of Public Health, 1991, 81:168-171.

11. Kelly JA et al. Community AIDS/HIV risk reduction: the effects of endorsements by popular people in three cities. American Journal of Public Health, 1992, 82:1483-1489.
12. Kelly JA et al. Randomised, controlled, community-level HIVprevention intervention for sexual-risk behavior among homosexual men in US cities. Lancet, 1997, 350:1500-1505.

13. Peer education and HIV/AIDS: concepts, uses and challenges. Geneva, Joint United Nations Programme on HIV/AIDS, 1999 (UNAIDS/99.46E).

14. Strecher VJ, Rosenstock IM. The health belief model. In: Glanz $\mathrm{K}$, Lewis FM, Rimer BK, eds. Health behavior and health education theory: research and practice, 2th ed. San Francisco, California, Jossey-Bass 1997:41-59.

15. Borgia $\mathrm{P}$ et al. Is peer-led education the best approach for HIV prevention in schools? Finding from a randomized controlled trial. Journal of Adolescent Health, 2009, 36:508-516.

16. Mellanby AR et al. A comparative study of peer-led and adultled school sex education. Health Education Research, 2001, 16:481-492.

17. Mellanby AR et al. School sex education: an experimental programme with educational and medical benefits. British Medical Journal, 1995, 331:414-417.

18. Eshrati B et al. Prevention HIV transmission among Iranian prisoners: Initial support for providing education on benefits of harm reduction practices. Harm Reduction Journal, 2008, 5:21.

19. Hounton $\mathrm{SH}$, Carabin H, Henderson NJ. Towards an understanding of barriers to condom use in rural Benin using the Health Belief Model: a cross sectional survey. BMC Public Health, 2005, 5:8.

20. Hasanian M. Cultural Approach to HIV/AIDS harm reduction in Muslim countries. Harm Reduction Journal, 2005, 2:23.

21. Utech DA, Hoving KL. Parents and peer-leds as competing influences in decisions practice: developing of differing ages. Journal of Social Psychology, 1969, 78:267-274.

22. Lindensy BJ. Peer-led education: a view point and critique. Journal of American College Health, 1996, 45:187-189. 